\title{
Reduced Risk of Reoperation Using Intramedullary Nailing with Femoral Neck Protection in Low-Energy Femoral Shaft Fractures
}

Hans Peter Bögl, Georg Zdolsek, Karl Michaelsson, Jonas Hoijer and Jörg Schilcher

The self-archived postprint version of this journal article is available at Linköping University Institutional Repository (DiVA):

http://urn.kb.se/resolve?urn=urn:nbn:se:liu:diva-171002

N.B.: When citing this work, cite the original publication.

Bögl, H. P., Zdolsek, G., Michaelsson, K., Hoijer, J., Schilcher, J., (2020), Reduced Risk of Reoperation Using Intramedullary Nailing with Femoral Neck Protection in Low-Energy Femoral Shaft Fractures, Journal of Bone and Joint Surgery. American volume, 102(17), 1486-1494.

https://doi.org/10.2106/JBJS.20.00160

Original publication available at:

https://doi.org/10.2106/JBJS.20.00160

Copyright: Lippincott, Williams \& Wilkins

http://www.lww.com/ 


\title{
Reduced risk for reoperation when using
}

\section{intramedullary nailing with protection of the femoral neck}

\section{in low-energy femoral shaft fractures}

\author{
Hans Peter Bögl M.D. ${ }^{1,2}$, Georg Zdolsek MS², Karl Michaëlsson M.D., Ph.D. ${ }^{3}$ \\ Jonas Höijer ${ }^{3}$ M.Sc., and Jörg Schilcher M.D., Ph.D. ${ }^{2}$
}

${ }^{1}$ Department of Orthopedic Surgery, Gävle hospital, Gävle, Sweden

${ }^{2}$ Department of Orthopedics in Linköping, and Department of Biomedical and Clinical Sciences, Linköping University, Linköping, Sweden

${ }^{3}$ Section of Orthopedics, Department of Surgical Sciences, Uppsala University, Uppsala, Sweden

\section{Corresponding author}

Hans Peter Bögl

Department of Orthopedic Surgery

Gävle Hospital

Lasarettsvägen 5

SE-80324 Gävle

Sweden

hans.peter.bogl@,regiongavleborg.se 


\begin{abstract}
Background

In Sweden, approximately one in four women aged 50 years or older will sustain a hip fracture. Patients treated for a femoral shaft fracture are likely to have an even higher risk. We hypothesized that intramedullary nails (IMN) protecting the femoral neck reduce the risk of subsequent hip fracture and allow the patient to avoid a challenging reoperation.
\end{abstract}

\title{
Methods
}

Between 2008 and 2010, 5,475 fractures of the femoral shaft, in patients aged $\geq 55$ years, were registered in Sweden. Of these, 897 patients fulfilled the inclusion criteria. We used radiographs and register data to identify reasons for and types of reoperation that occurred between the index surgery and December 31,2014. Categories of implants were determined through review of $\mathrm{x}$-rays as: IMN with protection of the femoral neck (FNP) and without protection of the femoral neck (NFNP). Reoperations related to peri-implant fractures (including hip fractures), were analyzed as a subgroup of all major reoperations. Multivariable-adjusted, cause-specific hazard ratios (csHRs) were calculated to compare the risk for reoperation between nails with FNP and NFNP.

Results

Among the 897 patients, a total of 82 reoperations were performed. In 640 patients who were treated with IMN with FNP, there were 7 peri-implant fractures (no hip fractures), and 27 major reoperations. Among the 257 patients who were treated with IMN with NFNP, 14 periimplant hip fractures and 24 major reoperations were identified. Patients who received nails with FNP had a lower hazard for any peri-implant fracture and major reoperation, with multivariable-adjusted csHR values of 0.19 (95\% CI 0.07-0.5) and $0.51(0.28-0.92)$, respectively. 


\section{Conclusions}

Intramedullary nails with femoral neck protection in the treatment of low-energy femoral shaft fractures prevent secondary hip fractures and decrease the overall risk for reoperation for 4-6 years postoperatively.

Level of Evidence

Level III 


\section{Introduction}

Scandinavian countries have the highest rates of hip fracture for women worldwide ${ }^{1,2}$. About one in four women aged $\geq 50$ years will sustain a hip fracture during their remaining lifetime ${ }^{3}$. Patients who receive treatment for a femoral shaft fracture are likely to have an increased risk of hip fracture due to risk factors associated with the initial fracture ${ }^{4-6}$, e.g., ethnicity, osteoporosis, impaired balance, drug use, smoking $^{7-9}$, but also due to debilitated lower extremity function and deterioration of biomechanics ${ }^{10,11}$.

The choice of implant for the fixation of femoral shaft fractures in patients who are at high risk for future fractures may have a significant impact on the outcomes. The standard of care for femoral shaft fractures is fixation with a reamed intramedullary nail ${ }^{12}$. However, it is not known whether a standard interlocking nail or a nail that allows fixation of the femoral head and neck is preferable when the goal is to avoid future femoral neck fractures. It seems reasonable to use an implant that incorporates the most fragile area of the extremity into the fixation. However, the use of nails with fixation of the femoral neck is suggested to entail risks for joint penetration, increased surgical time and avascular necrosis of the femoral head $^{13,14}$. During a review of patients with atypical femur fractures (AFF) we noted that the most common reason for reoperation was peri-implant fracture, i.e., hip fracture proximal to a previously inserted standard antegrade nail. In those patients who were treated with nails protecting the femoral neck, no such complications occurred ${ }^{15}$. Those were incidental findings and the numbers were low. Therefore, we hypothesized that patients with femoral shaft fractures, atypical and others, treated with IMN with femoral neck protection, would have a lower risk of peri-implant fracture than those patients who were treated with standard antegrade nails, in a nationwide cohort of patients with femoral shaft fractures ${ }^{16,17}$. Furthermore, we hypothesized that the overall risk for major reoperations would be lower owing to a more complete fixation of the whole femoral bone. 


\section{Patients and Methods}

\section{Study population}

Patients aged $\geq 55$ years who were admitted for a low-energy femoral shaft fracture (International Classification of Diseases, 10th Revision [ICD-10] diagnosis code S722 or S723 with external-cause code W) between January 1, 2008 and December 31, 2010 were identified in the Swedish National Inpatient Register (NPR) in our previous study ${ }^{16}$. Radiographs from all hospitals in Sweden were retrieved and individually re-evaluated regarding fracture classification, as described previously ${ }^{16,17}$. In cases of bilateral fractures, only the first fracture was included. Of the 5,475 identified patients, 4,351 were excluded (Figure 1). The source population for this investigation comprised 1,124 patients, of which 172 patients had atypical femoral fractures ${ }^{16}$.

\section{Identification of implants, reoperations and fracture classification}

In a first step, we retrieved all the follow-up, ipsilateral radiographic images from all the radiology departments in Sweden $(n=76)$, acquired between the date of the initial fracture and December 31, 2014. All the images were screened for any changes in the morphology of the bone, the fracture type, the type of fixation device used, and any alterations of the fixation device that indicated a reoperation. Implants were divided into groups (Figure 2): The first group were all IMN with femoral neck protection (FNP) (i.e., cephalomedullary and reconstruction nails). The second group comprised all antegrade (AMN) and retrograde (RMN) IMN with no femoral neck protection (NFNP). All patients with other fixation devices, and those who were treated non-operatively were excluded. The localization of the fracture was divided into subtrochanteric (from the lesser trochanter and 5-cm distal) and diaphyseal (from 5-cm distal to the lesser trochanter to the supracondylar flare) ${ }^{18}$. 
Reoperations were analyzed by two different approaches. In the primary approach we analyzed any peri-implant fracture in the ipsilateral femur that occurred during the followup period. In a second approach we analyzed all major reoperations together (including any peri-implant fracture, complete implant removal, revision osteosynthesis due to nonunion, implant failure, revision with joint arthroplasty in presence of non-union). For subgroup analyses, we also defined proximal peri-implant hip fractures (i.e., femoral neck or pertrochanteric fracture) and minor reoperations (partial implant removal, dynamization procedures, joint arthroplasty due to secondary osteoarthritis or avascular necrosis of the femoral head, and unspecified procedures). In patients that underwent more than one reoperation $(\mathrm{N}=21)$, the most complex reoperation was applied in the statistical analyses. The time interval between the initial fracture and reoperation was calculated in days. After radiographic review, we excluded 227 patients due to: plate osteosynthesis of the initial fracture $(\mathrm{N}=128)$, incomplete radiographic imaging $(\mathrm{N}=51)$, pre-existent implants $(\mathrm{N}=39)$, and other reasons $(\mathrm{N}=9)$.

In a second complementary step, we retrieved data from the NPR on every readmission of each patient from the initial fracture admission cohort until December 31, 2014. Only readmissions with discharge codes that indicated a relationship to the index fracture were considered (Supplementary Table 1). Through this complementary analysis, an additional 13 reoperations were identified. The final study cohort included 897 patients, of which 160 had atypical femoral fractures (Figure 1).

\section{Registers}

In Sweden, all permanent residents are provided with a unique personal identification number that allows complete linkage of all nationwide registers. Data on drug use and discharge diagnoses were collected from these registers ${ }^{16,19}$. 


\section{Statistical analysis}

The risks for peri-implant fracture and major reoperation were calculated for FNP and NFNP, separately. Age-adjusted odds ratios (ORs, using unconditional logistic regression) and relative risks (RRs, using log-binomial regression) were then calculated separately for reoperations related to peri-implant fractures and major reoperations. The ORs and RRs were then adjusted for the following predefined variables: age, sex, Charlson comorbidity index, and corticosteroid treatment. In addition, we performed a time-to-event analysis using Cox regression to estimate the age-, sex- and multivariable-adjusted, cause-specific hazard ratios (csHRs) for peri-implant fractures and major reoperations. The proportional hazards assumption was verified using log-log plots and Schoenfeld residuals plots. Since we observed differences in mortality between the groups, we calculated sub-distribution hazard ratios (sdHRs) using the Fine and Gray proportional sub-distribution hazard regression (sdHR) model.

\section{Subgroups}

To account for possible differences in reoperation rates related to fracture localization (diaphyseal or subtrochanteric) and type of fracture (atypical or common), we performed stratified analyses. Peri-implant fractures were analyzed in subgroups depending on their location proximal or distal to the intramedullary nail. Minor reoperations were analyzed separately.

The Stata (version 15) and IBM SPSS (version 25) software packages were used for the statistical analyses. 


\section{Sources of Funding}

This study was supported by ALF Grants, Region Östergötland and the Swedish Society of Medicine.

\section{Results}

The characteristics of the patients and implants are listed in Table 1. The median age of the participants was 83 years (IQR 75-88 years).

At the end of follow-up (median 5.4 years, IQR 4.7-6.1 years), a total of 82 reoperations were performed. Of these, 51 patients underwent major reoperations (21 peri-implant fractures) and 31 minor reoperations (Tables 2 and 3). The risk for reoperation due to periimplant fracture was $1.1 \%$ in the nails with FNP group (7/640 patients) and 5.4\% in the NFNP group (14/257), corresponding to a number needed to treat (NNT) of 23. In the nails with FNP group, there were no proximal peri-implant fractures, whereas 14 patients in the nails with NFNP group sustained proximal peri-implant hip fractures (Figure 3) at a median of 2.2 years (IQR 0.13-6.34 years). We observed seven distal peri-implant fractures in the nails with FNP group, whereas no such fractures were observed in the nails with NFNP group.

The risk for major reoperation was $4.2 \%$ in the nails with FNP group (27/640 patients) and $9.3 \%$ in the NFNP group (24/257 patients) (Table 2), corresponding to an NNT of 20.

Treatment using nails with FNP resulted in a five-fold lower risk for reoperation due to periimplant fracture, OR 0.18 (95\% CI 0.07-0.46), and the risk for major reoperations was halved, OR 0.44 (95\% CI 0.24-0.79). These ORs remained unchanged even after adjustment (Table 2). Reoperations due to peri-implant fractures in the nails with NFNP group were performed after a median of 0.28 years (IQR $0.08-0.53$ ), compared to 1.9 years (IQR $0.58-$ 
2.7) for the nails with FNP group. Similar differences between the groups were seen for major reoperations (Table 2).

Patients who were treated with nails with NFNP tended to be younger (Table 1). During the observation period, 359 patients (56.1\%) in the nails with FNP group and 101 patients $(39.3 \%)$ in the nails with NFNP died. Taking the resulting differences in follow-up time into account, the hazard ratios for reoperation remained stable; the multivariable-adjusted sdHR values were 0.2 (95\% CI 0.07-0.54) for peri-implant fractures and 0.51 (95\% CI $0.28-0.93)$ for major reoperations.

\section{Subgroup analysis}

Patients with subtrochanteric fracture $(\mathrm{N}=515)$ were almost exclusively treated with nails with FNP $(\mathrm{N}=506)$. Among the nine patients who received nails with NFNP, one underwent reoperation due to a subsequent hip fracture. Five reoperations were needed for peri-implant fractures in the nails with FNP group; the multivariable-adjusted csHR was 0.07 (95\% CI 0.01-0.7). In patients with femoral shaft fractures, the risk for peri-implant fracture was lower in the nails with FNP group (2/134) than in the nails with NFNP group (13/248), multivariable-adjusted csHR 0.27 (95\% CI 0.06-1.22).

Despite their pre-existing osteoporosis, more than half 54.4\% (87/160) of the patients with atypical femoral fractures were treated with nails with NFNP. Among the patients with common femoral fractures, $23.1 \%$ were treated with nails with NFNP. In patients with AFF who received treatment with NFNP nails $(\mathrm{N}=87), 6$ peri-implant fractures and 14 major reoperations occurred, as compared to 3 peri-implant fractures and 7 major reoperations in the patients with AFF who received treatment with FNP nails $(\mathrm{N}=73)$. 


\section{Discussion}

Our hypothesis was that IMN that protected the femoral neck would reduce the risk of reoperation, in particular for future hip fractures, in patients with femoral shaft fractures that were treated with IMN. In line with this hypothesis, we discovered a 5-fold risk reduction of any peri-implant fracture in the FNP group, compared to the use of standard nails, and the risk for major reoperations in the FNP group was reduced by half. The results remained essentially unchanged after correction for differences in baseline characteristics and death.

Our results are very clear and in line with our expectations. However, the use of nails with protection of the femoral neck for the treatment of low-energy femoral shaft fractures is not as frequent as one would expect. More than $50 \%$ of the patients with atypical femoral fractures related to bisphosphonate treatment for osteoporosis in our cohort were treated with a standard antegrade nail. These findings are not unique for the Swedish subpopulation of atypical fracture patients ${ }^{20-23}$.

The literature on implant choices in the treatment of common femoral shaft fractures is sparse. Only a few case reports have addressed the problem of proximal peri-implant fractures $^{24-26}$, but there is no apparent consensus regarding the use of a specific type of implant in elderly patients. Reconstruction and cephalomedullary nails (CMNs) have been designed to protect patients with metastatic bone disease from late fractures caused by new lesions $^{27,28}$. Subsequently, indications for these nails have been extended, but their use in metastatic bone disease has been questioned due to increased costs, limited benefit to the patient and the possible risks of perioperative joint penetration, increased surgical time, fluoroscopic exposure ${ }^{13}$ and avascular necrosis of the femoral head ${ }^{14,29}$. Though theoretically possible, avascular necrosis following screw insertion into the femoral head seems negligible, even when the vascular supply is compromised by both a fracture and the fixation ${ }^{14,30}$. 
Because CMNs are so commonly used today, the problem of increased surgical time, increased fluoroscopic exposure and even implant costs appears less relevant ${ }^{14}$. Patients who were treated with nails with NFNP underwent reoperation much earlier compared to the nails with FNP group (Table 2) and the most common reason for reoperation due to periimplant fracture was fracture of the hip. The short time interval to reoperation might indicate that the hip fracture was an associated injury already at the time of the shaft fracture ${ }^{31}$. Based on our review of individual radiographs, such a mechanism is highly unlikely.

We did not observe any distal peri-implant fractures in the group that received nails with

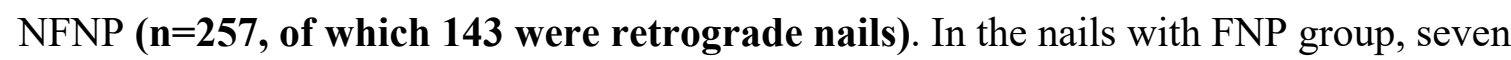
such fractures occurred in the group that received CMNs $(\mathbf{n}=\mathbf{5 7 0})$. Two of these seven patients were operated with CMNs that did not reach beyond the femoral isthmus. The remaining five patients were operated with longer $\mathrm{CMNs}$, with a median distance from the tip of the CMN to the Blumensaat's line of $82 \mathrm{~mm}$ (IQR 35-95 mm). All nails were distally locked. One anterior perforation was observed. The problem of anterior perforation and the mismatch between femoral and nail radius of curvature is well-documented ${ }^{32-34}$, and might prompt the surgeon to choose a shorter nail that leaves the distal part of the femur unprotected. While we believe that increasing working length of the nail and individualizable radius of nail curvature should decrease the risk for distal complications ${ }^{33-35}$, further studies will be needed to elucidate this problem.

The more advanced age of the patients in the group with nails with FNP resulted in a shorter follow-up period. Therefore, death becomes a strong competitor for reoperation, which means that death hinders the occurrence of a reoperation. Moreover, applying a lower demand for physical performance and a higher threshold for revision of an implant in elderly and comorbid patients might have contributed to the differences in the reoperation rate. However, 
when we corrected our analyses for differences in background characteristics, the risk differences remained stable. An alternative explanation for the differences is selection bias. Retrograde nails might be selected for cases with a higher risk for complications, such as fractures distal to the femoral isthmus ${ }^{36}$ or obese patients ${ }^{37}$.

Major strengths of our study are the nationwide coverage and complete linkage between highquality registers and radiographic adjudication of fracture type and location, as well as our rigorous identification of reoperations using two complementary methods. This validation process was time-consuming, and our endpoints therefore are greater than 5 years old. Another fundamental limitation is the absence of proximal peri-implant fractures in the FNP group which prohibited statistical calculations of the risk difference. Other limitations include the potential for selection (e.g. patient ambulatory status) and indication as well as expertise bias. Also, residual confounding might occur due to undetected selection mechanisms related to implant type. Differences in such factors between the two types of fixation could affect our estimates. As the majority of the patients in our cohort are of Caucasian origin, our results should be extrapolated to other ethnic groups with caution. This is especially true for atypical femoral fractures, which are coupled to ethnicity and biomechanical aspects of femoral geometry ${ }^{38,39}$, as well as differences in femoral neck bone density and strength ${ }^{26}$. Despite the relatively high number of patients in our cohort, the proportion of patients with reoperations was about $10 \%$, resulting in a moderate level of precision for our estimates.

Our results suggest that surgery using nails with FNP effectively prevents future hip fractures when used for femoral shaft fractures in the aged patient. In the present study cohort, about 18 patients would have to be treated with nails with FNP to prevent one subsequent hip fracture. With a median follow-up time of 5.4 years, our results can be compared to those of efficacy 
trials with targeted pharmacotherapy for osteoporosis (i.e., bisphosphonates), which have shown that 667 patients need to be treated for one year ${ }^{40,41}$ and 175 patients need to be treated for three years to prevent one hip fracture ${ }^{42}$.

Considering that proximal peri-implant fractures represented the most common reason for any major reoperation in the nails with NFNP group and that no such fractures occurred in the nails with FNP group, we propose that IMN with FNP should be the primary choice of fixation in older patients with femoral shaft fractures. In this group of patients, this simple change of implant type has the potential to achieve a substantial reduction in the reoperation rate.

\section{Acknowledgments}

We thank our deceased colleague Per Aspenberg for intellectual contributions and support, and all the radiology departments throughout Sweden for their willingness to provide radiographs.

\section{References}

1. Veronese N; Maggi S. Epidemiology and social costs of hip fracture. Injury. 2018 Aug;49(8):1458-1460, doi: 10.1016/j.injury.2018.04.015.

2. Kanis JA; Oden A; McCloskey EV; Johansson H; Wahl DA; Cooper C et al. A systematic review of hip fracture incidence and probability of fracture worldwide. Osteoporos Int. 2012 Sep;23(9):2239-56, doi: 10.1007/s00198-012-1964-3.

3. Lofman O. [Osteoporosis fracture epidemiology]. Lakartidningen. 2006 Oct 410;103(40):2956-8.

4. Cosman F; de Beur SJ; LeBoff MS; Lewiecki EM; Tanner B; Randall S et al. Clinician's Guide to Prevention and Treatment of Osteoporosis. Osteoporosis International. 2014 2014/10/01;25(10):2359-2381, doi: 10.1007/s00198-014-2794-2.

5. Black DM; Arden NK; Palermo L; Pearson J; Cummings SR. Prevalent vertebral deformities predict hip fractures and new vertebral deformities but not wrist fractures. Study of Osteoporotic Fractures Research Group. J Bone Miner Res. 1999 May;14(5):821-8, doi: 10.1359/jbmr.1999.14.5.821.

6. Kanis JA. Diagnosis of osteoporosis and assessment of fracture risk. The Lancet. 2002;359(9321):1929-1936, doi: 10.1016/s0140-6736(02)08761-5. 
7. Wiklund R; Toots A; Conradsson M; Olofsson B; Holmberg H; Rosendahl E et al. Risk factors for hip fracture in very old people: a population-based study. Osteoporos Int. 2016 Mar;27(3):923-931, doi: 10.1007/s00198-015-3390-9.

8. Wagner H; Melhus H; Gedeborg R; Pedersen NL; Michaelsson K. Simply ask them about their balance--future fracture risk in a nationwide cohort study of twins. Am J Epidemiol. 2009 Jan 15;169(2):143-9, doi: 10.1093/aje/kwn379.

9. Lagerros YT; Hantikainen E; Michaelsson K; Ye W; Adami HO; Bellocco R. Physical activity and the risk of hip fracture in the elderly: a prospective cohort study. Eur J Epidemiol. 2017 Nov;32(11):983-991, doi: 10.1007/s10654-017-0312-5.

10. Larsen P; Elsoe R; Graven-Nielsen T; Laessoe U; Rasmussen S. Decreased muscle strength is associated with impaired long-term functional outcome after intramedullary nailing of femoral shaft fracture. Eur J Trauma Emerg Surg. 2015 Dec;41(6):673-81, doi:

10.1007/s00068-014-0488-2.

11. Elmi. Comparison of Outcome of Femoral Shaft Fracture Fixation with Intramedullary Nail in Elderly Patient and Patients Younger than 60 Years Old. THE ARCHIVES OF BONE AND JOINT SURGERY. 2014.

12. Neumann MV; Sudkamp NP; Strohm PC. Management of femoral shaft fractures. Acta Chir Orthop Traumatol Cech. 2015;82(1):22-32.

13. Moon B; Lin P; Satcher R; Bird J; Lewis V. Intramedullary nailing of femoral diaphyseal metastases: is it necessary to protect the femoral neck? Clin Orthop Relat Res. 2015 Apr;473(4):1499-502, doi: 10.1007/s11999-014-4064-1.

14. Collinge C; Liporace F; Koval K; Gilbert GT. Cephalomedullary screws as the standard proximal locking screws for nailing femoral shaft fractures. J Orthop Trauma. 2010 Dec;24(12):717-22, doi: 10.1097/BOT.0b013e3181f6bfe8.

15. Schilcher J. High revision rate but good healing capacity of atypical femoral fractures. A comparison with common shaft fractures. Injury. 2015 Oct 8, doi:

10.1016/j.injury.2015.09.031.

16. Schilcher J; Koeppen V; Aspenberg P; Michaelsson K. Risk of atypical femoral fracture during and after bisphosphonate use. Acta Orthop. 2015 Feb;86(1):100-7, doi: 10.3109/17453674.2015.1004149.

17. Schilcher J; Koeppen V; Aspenberg P; Michaelsson K. Risk of atypical femoral fracture during and after bisphosphonate use. N Engl J Med. 2014 Sep 4;371(10):974-6, doi: 10.1056/NEJMc1403799.

18. Kootstra G. Femoral Shaft Fractures in Adults : A study of 329 consecutive cases with a statistical analysis of different methods of treatment. [S.n.]. 1973 1973/11/21:163.

19. Kharazmi M; Hallberg P; Schilcher J; Aspenberg P; Michaelsson K. Mortality After Atypical Femoral Fractures: A Cohort Study. J Bone Miner Res. 2016 Mar;31(3):491-7, doi: 10.1002/jbmr.2767.

20. Schilcher J; Michaelsson K; Aspenberg P. Bisphosphonate use and atypical fractures of the femoral shaft. N Engl J Med. 2011 May 5;364(18):1728-37, doi:

10.1056/NEJMoa1010650.

21. Egol KA; Park JH; Rosenberg ZS; Peck V; Tejwani NC. Healing delayed but generally reliable after bisphosphonate-associated complete femur fractures treated with IM nails. Clin Orthop Relat Res. 2014 Sep;472(9):2728-34, doi: 10.1007/s11999-013-2963-1.

22. Lee KJ; Yoo JJ; Oh KJ; Yoo JH; Rhyu KH; Nam KW et al. Surgical outcome of intramedullary nailing in patients with complete atypical femoral fracture: A multicenter retrospective study. Injury. 2017 Apr;48(4):941-945, doi: 10.1016/j.injury.2017.02.036. 23. Lim HS; Kim CK; Park YS; Moon YW; Lim SJ; Kim SM. Factors Associated with Increased Healing Time in Complete Femoral Fractures After Long-Term Bisphosphonate Therapy. J Bone Joint Surg Am. 2016 Dec 7;98(23):1978-1987, doi: 10.2106/JBJS.15.01422. 
24. Schilcher J. High revision rate but good healing capacity of atypical femoral fractures. A comparison with common shaft fractures. Injury. 2015 Dec;46(12):2468-73, doi:

10.1016/j.injury.2015.09.031.

25. Moran CG; Gibson MJ; Cross AT. Intramedullary locking nails for femoral shaft fractures in elderly patients. J Bone Joint Surg Br. 1990 Jan;72(1):19-22.

26. Tano A; Oh Y; Fukushima K; Kurosa Y; Wakabayashi Y; Fujita K et al. Potential bone fragility of mid-shaft atypical femoral fracture: Biomechanical analysis by a CT-based nonlinear finite element method. Injury. 2019 Nov;50(11):1876-1882, doi:

10.1016/j.injury.2019.09.004.

27. Karachalios T; Atkins RM; Sarangi PP; Crichlow TP; Solomon L. Reconstruction nailing for pathological subtrochanteric fractures with coexisting femoral shaft metastases. $\mathrm{J}$ Bone Joint Surg Br. 1993 Jan;75(1):119-22.

28. Levine A. Treatment of Metastatic Lesions of the Femur With Locked Intramedullary Rod Fixation. 1989.

29. Moon B; Lin P; Satcher R; Bird J; Lewis V. Intramedullary Nailing of Femoral Diaphyseal Metastases: Is it Necessary to Protect the Femoral Neck? Clinical Orthopaedics and Related Research ${ }^{\circledR} .2014 ; 473(4): 1499-1502$, doi: 10.1007/s11999-014-4064-1.

30. Bojan AJ; Beimel C; Speitling A; Taglang G; Ekholm C; Jonsson A. 3066 consecutive Gamma Nails. 12 years experience at a single centre. BMC Musculoskelet Disord. 2010 Jun 26;11:133, doi: 10.1186/1471-2474-11-133.

31. Boulton CL; Pollak AN. Special topic: Ipsilateral femoral neck and shaft fractures-does evidence give us the answer? Injury. 2015 Mar;46(3):478-83, doi:

10.1016/j.injury.2014.11.021.

32. Fantry AJ; Elia G; Vopat BG; Daniels AH. Distal femoral complications following antegrade intramedullary nail placement. Orthop Rev (Pavia). 2015 Mar 3;7(1):5820, doi: 10.4081 /or.2015.5820.

33. Shetty A; Shenoy PM; Swaminathan R. Mismatch of long Gamma intramedullary nail with bow of the femur: Does radius of curvature of the nail increase risk of distal femoral complications? J Clin Orthop Trauma. 2019 Mar-Apr;10(2):302-304, doi:

10.1016/j.jcot.2017.12.006.

34. Bazylewicz DB; Egol KA; Koval KJ. Cortical encroachment after cephalomedullary nailing of the proximal femur: evaluation of a more anatomic radius of curvature. J Orthop Trauma. 2013 Jun;27(6):303-7, doi: 10.1097/BOT.0b013e318283f24f.

35. Kim JW; Oh CW; Oh JK; Park KH; Kim HJ; Kim TS et al. Treatment of infra-isthmal femoral fracture with an intramedullary nail: Is retrograde nailing a better option than antegrade nailing? Arch Orthop Trauma Surg. 2018 Sep;138(9):1241-1247, doi: 10.1007/s00402-018-2961-6.

36. Watanabe Y; Takenaka N; Kobayashi M; Matsushita T. Infra-isthmal fracture is a risk factor for nonunion after femoral nailing: a case-control study. J Orthop Sci. 2013 Jan;18(1):76-80, doi: 10.1007/s00776-012-0316-7.

37. Tucker MC; Schwappach JR; Leighton RK; Coupe K; Ricci WM. Results of femoral intramedullary nailing in patients who are obese versus those who are not obese: a prospective multicenter comparison study. J Orthop Trauma. 2007 Sep;21(8):523-9, doi:

10.1097/BOT.0b013e31813347ac.

38. Schilcher J; Howe TS; Png MA; Aspenberg P; Koh JS. Atypical Fractures are Mainly Subtrochanteric in Singapore and Diaphyseal in Sweden: A Cross-Sectional Study. J Bone Miner Res. 2015 Nov;30(11):2127-32, doi: 10.1002/jbmr.2547.

39. Lo JC; Hui RL; Grimsrud CD; Chandra M; Neugebauer RS; Gonzalez JR et al. The association of race/ethnicity and risk of atypical femur fracture among older women receiving oral bisphosphonate therapy. Bone. 2016 Apr;85:142-7, doi: 10.1016/j.bone.2016.01.002. 
40. Jarvinen TL; Michaelsson K; Aspenberg P; Sievanen H. Osteoporosis: the emperor has no clothes. J Intern Med. 2015 Jun;277(6):662-73, doi: 10.1111/joim.12366.

41. Jarvinen TL; Sievanen H; Kannus P; Jokihaara J; Khan KM. The true cost of pharmacological disease prevention. BMJ. 2011 Apr 19;342:d2175, doi: 10.1136/bmj.d2175. 42. Jarvinen TL; Michaelsson K; Jokihaara J; Collins GS; Perry TL; Mintzes B et al. Overdiagnosis of bone fragility in the quest to prevent hip fracture. BMJ. 2015 May 26;350:h2088, doi: 10.1136/bmj.h2088.

Figure legends

Figure 1: Study cohort recruitment flow chart

$\mathrm{SCB}=$ Statistics Sweden; NPR $=$ Swedish National Patient Register; ICD $10=$

International Classification of Diseases, 10th Revision; FNP $=$ Femoral Neck

Protection; NFNP $=$ No Femoral Neck Protection.

Figure 2: Plain AP radiographs of the two different groups of IMN:

The femoral neck protection (FNP) group consists of cephalomedullary nails CMN (A) and reconstruction nails (B). The no femoral neck protection (NFNP) group comprises antegrade medullary nails $(\mathrm{AMN})(\mathrm{C})$ and retrograde intramedullary nails (RMN) (D).

Figure 3: Plain AP radiographs of a patient with atypical femoral fracture (A) treated with a standard antegrade intramedullary nail (B). A peri-implant fracture of the femoral neck (C) 5 months after the index surgery, was treated with a total hip replacement (D). 
Table 1. Patients' characteristics at baseline.

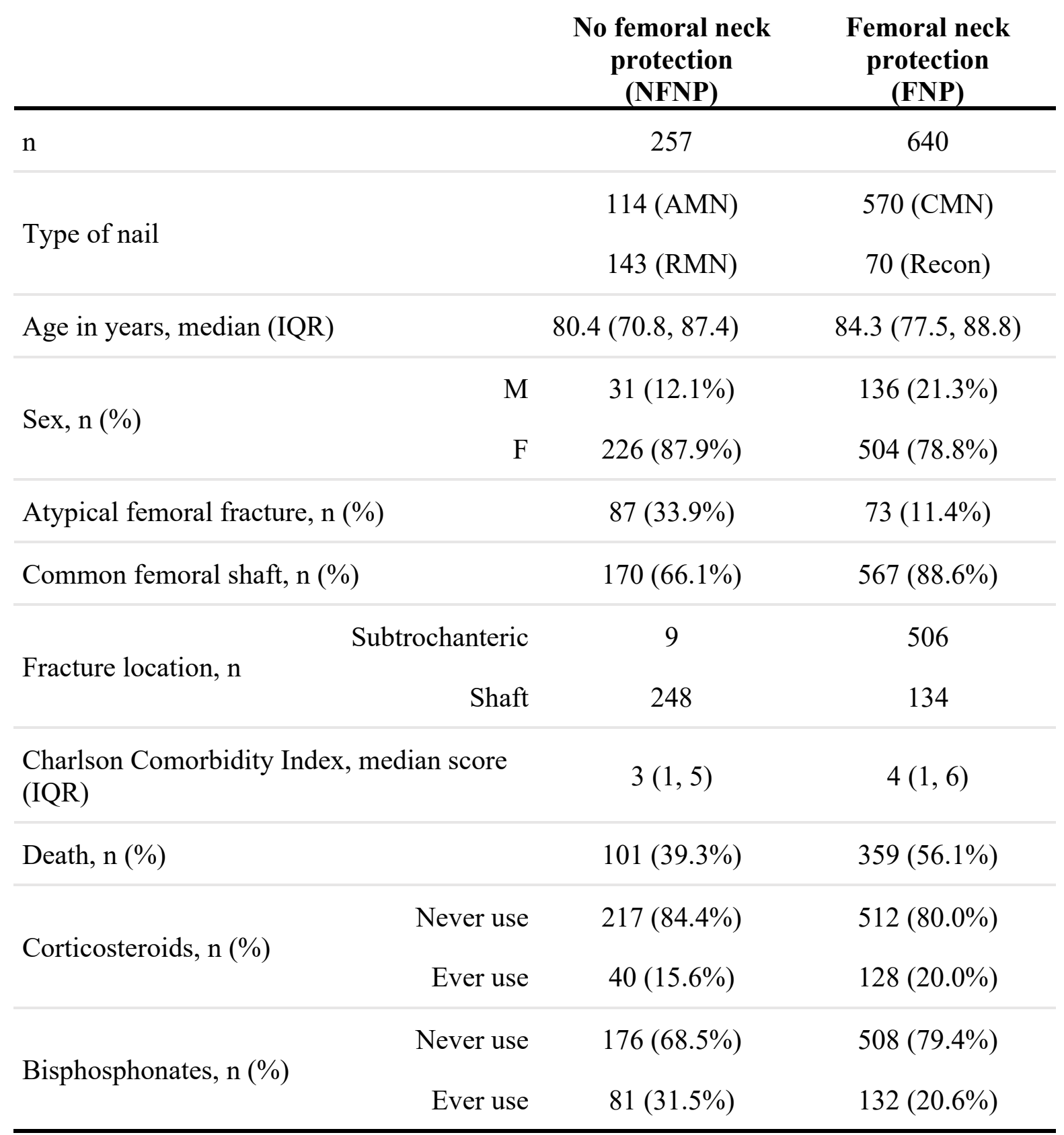

$\mathrm{AMN}$, antegrade intramedullary nail; $\mathrm{CMN}$, cephalomedullary nail; RMN, retrograde intramedullary nail; Recon, reconstruction nail; IQR, interquartile range. 
Supplementary Table 1. Reoperation procedures and related procedure codes (KVÅ, Swedish Classification for Health Procedures, i.e., Swedish version of the NOMESCO classification) and diagnostic codes (International Classification of Diseases, $10^{\text {th }}$ Revision)

\begin{tabular}{|c|c|}
\hline Type of procedure & KVÅ code \\
\hline Biopsy & NFA22, NFA32 \\
\hline Arthroplasty, primary & NFB19, NFB29, NFB39, NFB49 \\
\hline Arthroplasty, secondary & NFC40, NFC42, NFC99 \\
\hline Excision arthroplasty & NFG09 \\
\hline Joint reduction & NFH20 \\
\hline Ostheosynthesis & NFJ09, NFJ19, NFJ49, NFJ59, NFJ69, NFJ79, NFJ89, NFJ99 \\
\hline Other & NFK99, NGK99 \\
\hline Tendon repair/reconstruction & NFL99 \\
\hline Bone grafting & NFN09, NFN99 \\
\hline Transfemoral amputation & NFQ19 \\
\hline Incision and debridement & NFS09, NFS19, NFS29, NFS39, NFS99, NGS19, NGS49 \\
\hline Deformity correction & NFT49 \\
\hline Removal of hardware & NFU39, NFU49 \\
\hline Reoperation due to bleeding/infection & NFW79, NFW99 \\
\hline Synovectomy knee joint & NGF12 \\
\hline ICD 10 code & Description \\
\hline S72 & Fracture of femur \\
\hline T84 & $\begin{array}{l}\text { Complications of internal orthopedic prosthetic devices, } \\
\text { implants and grafts }\end{array}$ \\
\hline T81 & Complications of procedures not elsewhere classified \\
\hline T93 & Sequelae of injuries of lower limb \\
\hline M84 & Disorder of continuity of bone \\
\hline M80.9 & Osteoporosis with pathological fracture \\
\hline M96 & $\begin{array}{l}\text { Intraoperative and postprocedural complications and disorders } \\
\text { of musculoskeletal system, not elsewhere classified }\end{array}$ \\
\hline
\end{tabular}




\section{No femoral neck}

protection

(NFNP)
$n=257$
Femoral neck
protection
(FNP)

$\mathrm{n}=640$
Age- \& sex-
adjusted
OR $(95 \% \mathrm{CI})$

Multivariable-

adjusted

$\operatorname{csHR}^{1}(95 \% \mathrm{CI})$

adjusted

$\operatorname{sdHR}^{2}(95 \% \mathrm{CI})$

Proximal peri-implant fracture

$14(5.4 \%)$

$0(0.0 \%)$

$*$

$*$

Any peri-implant fracture

$14(5.4 \%)$

$7(1.1 \%)$

$0.18(0.07,0.46)$

$\mathbf{p}=\mathbf{0 . 0 0 0 4}$

$0.19(0.07,0.50)$

$\mathbf{p}=\mathbf{0 . 0 0 1}$

$0.20(0.07,0.54)$

$\mathbf{p}=\mathbf{0 . 0 0 2}$

Time to any peri-implant fracture (years), median (IQR)

$0.28(0.08,0.53)$

$1.9(0.58,2.7)$

\begin{tabular}{|c|c|c|c|c|c|}
\hline Major reoperation & $24(9.3 \%)$ & $27(4.2 \%)$ & $\begin{array}{c}0.44(0.24,0.79) \\
\mathbf{p}=\mathbf{0 . 0 0 7}\end{array}$ & $\begin{array}{c}0.51(0.28,0.92) \\
\mathbf{p}=\mathbf{0 . 0 3}\end{array}$ & $\begin{array}{c}0.51(0.28,0.93) \\
\mathbf{p}=\mathbf{0 . 0 3}\end{array}$ \\
\hline Time to major reoperation (years), median (IQR) & $0.53(0.08,1.0)$ & $1.14(0.37,2.5)$ & & & \\
\hline Minor reoperation & $12(4.7 \%)$ & $19(3.0 \%)$ & $\begin{array}{c}0.77(0.36,1.7) \\
\mathbf{p}=\mathbf{0 . 5 2}\end{array}$ & $\begin{array}{c}0.81(0.38,1.7) \\
\mathbf{p}=\mathbf{0 . 5}\end{array}$ & $\begin{array}{c}0.81(0.34,2.0) \\
\mathbf{p}=\mathbf{0 . 6 5}\end{array}$ \\
\hline
\end{tabular}

Time to minor reoperation (years), median (IQR)

$0.70(0.21,1.2)$

$0.56(0.07,0.85)$

* Could not be assessed as no event occurred in the FNP group.

1 cause-specific hazard ratios (csHR) were adjusted for age, sex, glucocorticoid use (yes or no), and Charlson comorbidity index score.

${ }^{2}$ sub-distribution hazard ratios (sdHRs) were calculated using the Fine and Gray proportional sub-distribution hazard regression model. 
Table 3. Frequencies of reoperations.

\begin{tabular}{|c|c|c|c|}
\hline Type of reoperation & Surgical procedure & $\begin{array}{c}\text { No femoral neck } \\
\text { protection } \\
\text { (NFNP) } \\
\mathrm{n}=257\end{array}$ & $\begin{array}{c}\text { Femoral neck } \\
\text { protection } \\
\text { (FNP) } \\
\mathrm{n}=640\end{array}$ \\
\hline \multirow{6}{*}{ Major } & Complete implant removal & $4(1.6 \%)$ & $1(0.2 \%)$ \\
\hline & Revision with plate osteosynthesis & $1(0.4 \%)$ & $6(0.9 \%)$ \\
\hline & Revision with IMN osteosynthesis & $5(1.9 \%)$ & $10(1.6 \%)$ \\
\hline & THR because of nonunion & $0(0 \%)$ & $3(0.5 \%)$ \\
\hline & Peri-implant hip fracture & $14(5.4 \%)$ & $0(0 \%)$ \\
\hline & Distal peri-implant fracture & $0(0 \%)$ & $7(1.1 \%)$ \\
\hline \multirow{4}{*}{ Minor } & Partial implant removal & $6(2.3 \%)$ & $6(0.9 \%)$ \\
\hline & Dynamizing procedures & $4(1.6 \%)$ & $5(0.8 \%)$ \\
\hline & THR because of OA & $0(0 \%)$ & $2(0.3 \%)$ \\
\hline & Other (arthroscopy, soft tissue procedures, ...) & $2(0.8 \%)$ & $6(0.9)$ \\
\hline None & & $221(86.0 \%)$ & $594(92.8 \%)$ \\
\hline
\end{tabular}

IMN, Intramedullary nail; THR, Total hip replacement; OA, Osteoarthritis. 


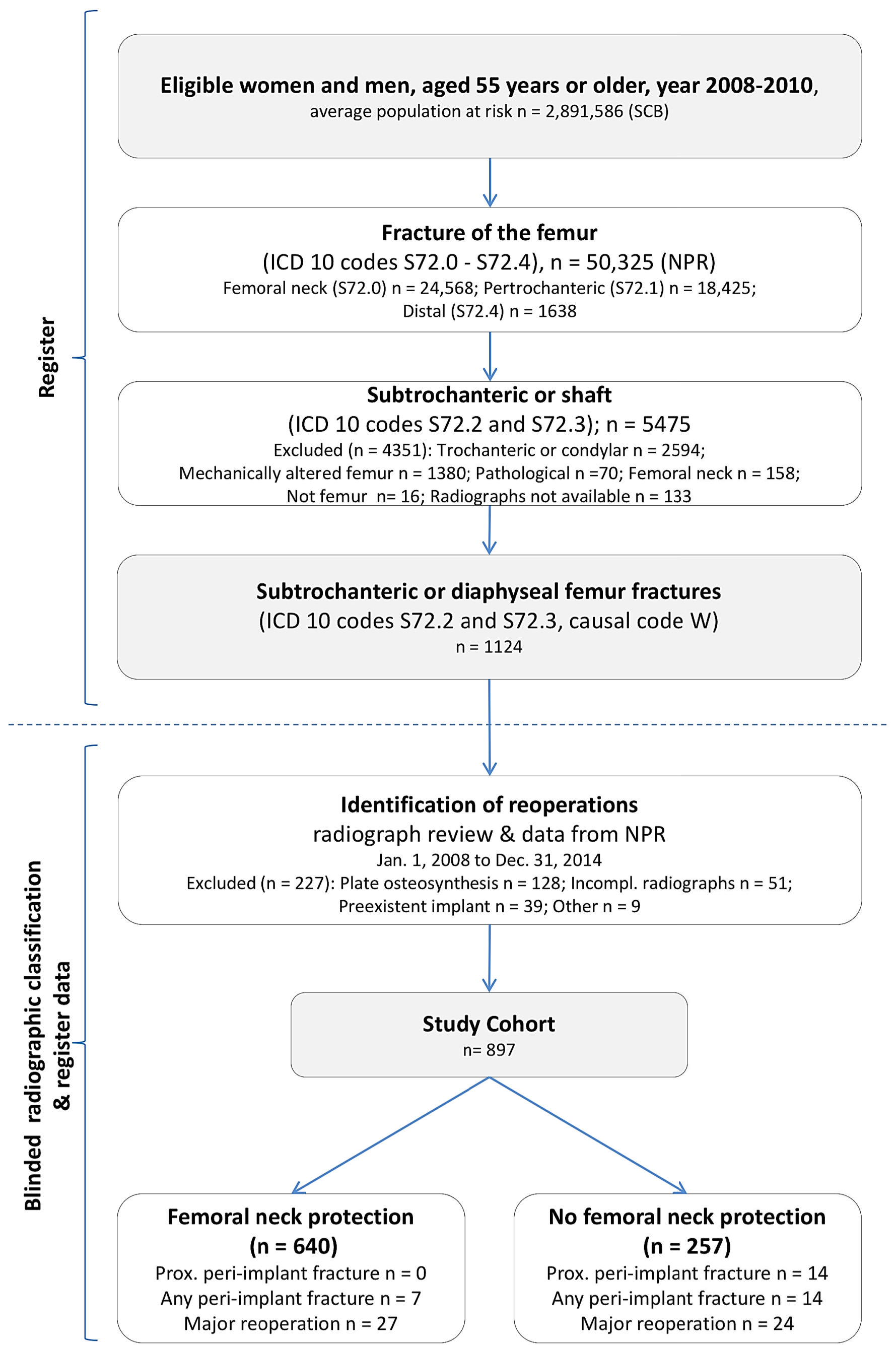




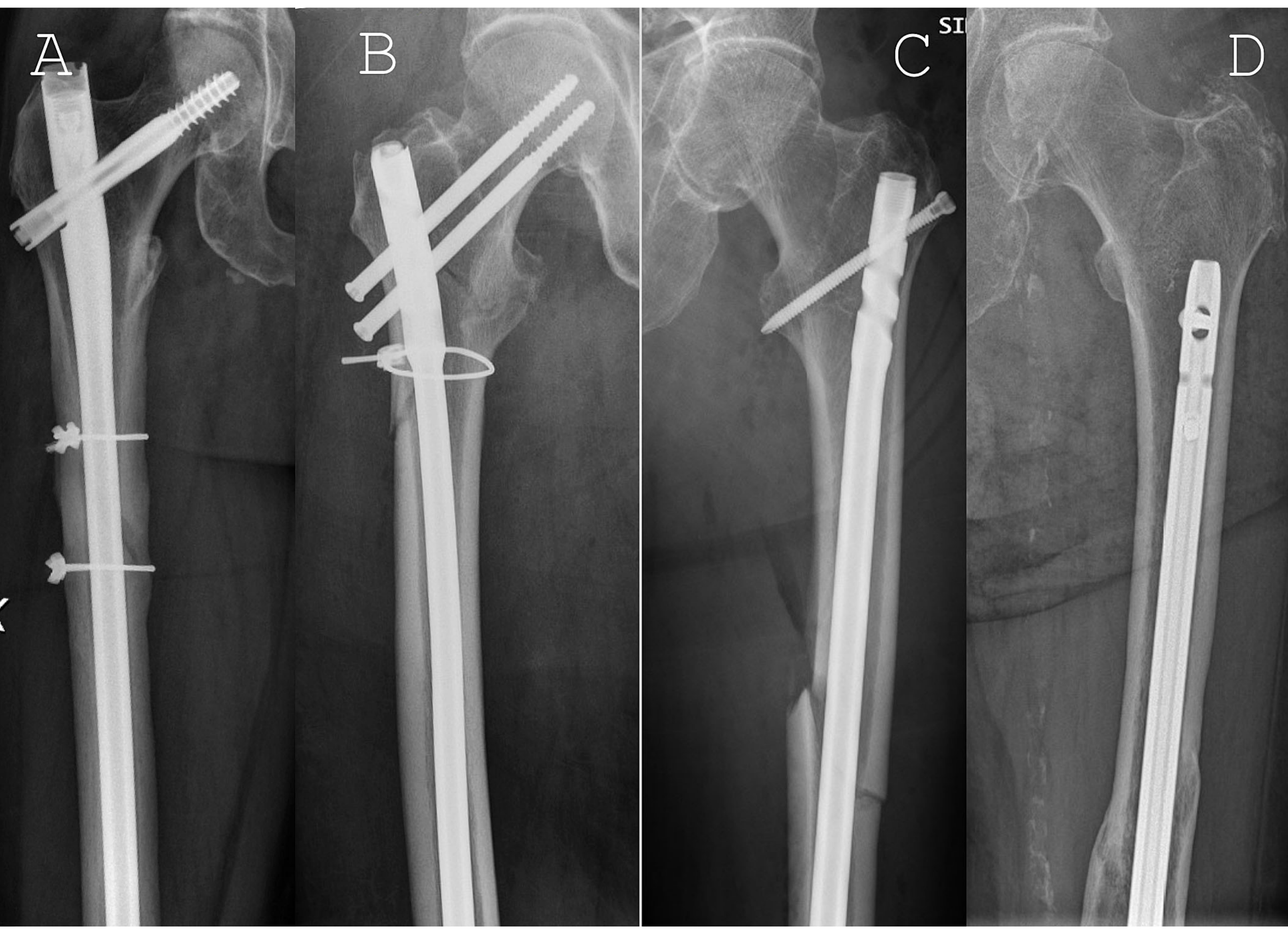




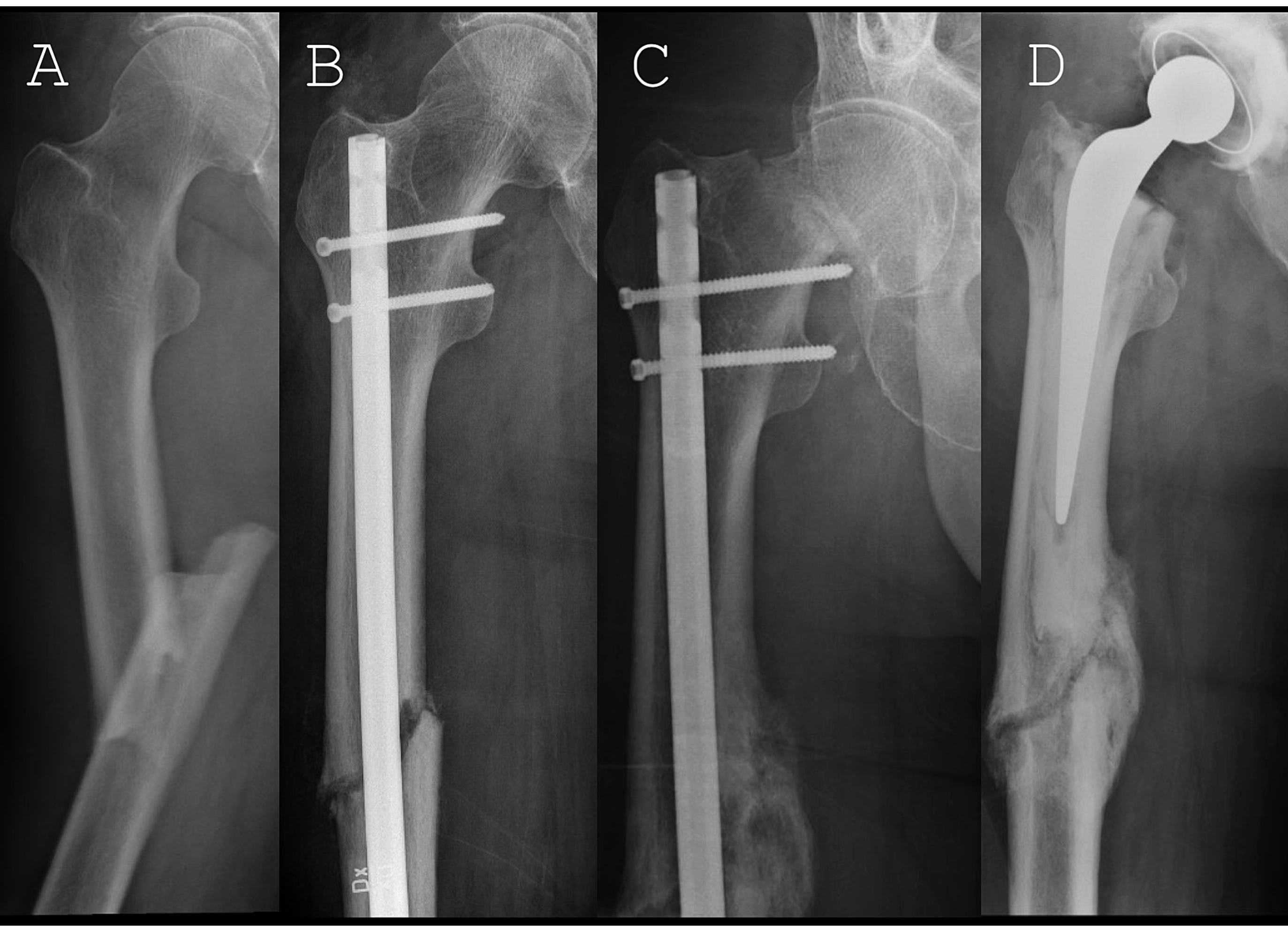

